\title{
Research on the Filial Piety of College Students under General Education
}

\author{
Fengzhen Jia \\ Xijing University, Xi'an Shaanxi province710123 \\ Shaanxi city of Xi'an province Changan District Xijing Road No. 1 \\ General education center of Xijing Universit, 710123 \\ jiazhen8588@126.com
}

Keywords: College students; Filial piety; Current situation; Reason; Implementation

\begin{abstract}
General education originated in nineteenth Century, and its ultimate goal is to develop a complete and full person. The lack of "filial piety" of the current college students is not optimistic: they narrowly understand the meaning of "filial piety", don't respect their parents feel, don't considerate parents arduous, lack of real action 、 and do not cherish the lives from their parents, In this case, how to cultivate a complete, and full college students. There are main following four aspects which lead to lack the "filial piety": The influence of the social atmosphere, the absence of the school education, the excess love of the family, the weakness of the students themselves. We have to base on foundation of analyzing the deep reasons to carry forward the essence of filial piety, and strengthen the cultivation of College Students' filial piety.
\end{abstract}

\section{Introduction}

General education focuses on "education" instead of "teaching", is a kind of humanistic education, and is to "breed" the real "human" rather than "product". Chinese nation with five thousand years history, has a splendid and brilliant culture, among them, "filial piety" is one of the excellent traditional virtues of the Chinese nation. As the great thinker and educator in our country, Confucius said, "the human filial piety is the root of moral, the origin of teaching ", Filial piety is the cornerstone of social morality, the fundamental origin of education. In the feudal society of our country, greatly advocate "the filial piety is the first of all kindness, is root of virtue", advocate "love all the old and the young". The "filial piety" integrates into the schools and become an important part of school education.

In the face of the traditional "filial piety", we should take the essence, discard the dross, it has of far-reaching practical significance for the contemporary college students' moral education and the college campus culture construction. The lack of "filial piety" of the current college students is not optimistic: But the lack of "filial piety" of the current college students is not optimistic, we have to base on foundation of analyzing the deep reasons to carry forward the essence of filial piety, and strengthen the cultural construction of College Students' campus.

\section{The Situation of Lacking “Filial Piety" in the Current College Students}

The situation of lacking "filial piety" in Current college students is not optimistic, then, what are the specific performance?

Narrowly Understand the Meaning of “Filial Piety”. Most college students on the meaning of filial piety are too narrow, simply think that it is to support their parents on materially and listen to their words. These understandings of "filial piety" are not wrong, but not comprehensive. For example, in addition to the need to support their parents materially and take care of them mentally, 
also should come back to visit them and talk with them in heart to communicate and understand adequately. Therefore, the perfect performance of "filial piety" is always to be responsible for the family, others, and the community.

Don't Respect Parents' Feeling. Parent's care and love for their children are selfless dedication and not for the return, for parents' words, most of them are worthy of our children to follow, most of them are worthy of our children to follow. But college students' self-consciousness is very strong, while slightly different with their opinions, they immediately try to resist and don't respect for the parents' feelings at all, which greatly hurts their parents' hearts. For example, some naive college students for the face, regardless of family burden, get money from parents to buy IPhone6, while parents cannot satisfy them, they will make a fuss, even threat to death.

Don't Understand Parents Hardships. Some students do not understand the hardships for their parents to support a family; even think that it is their duty to raise their children. They will not be considerate bitterness and tears behind of their parents to bring up their children grow up. From the infant child to university students, parents not only need to earn money to support, but also need to pay selfless care and love. But some students did not show solicitude for parents, but be blame that they are not a born -rich kids, parents are not millionaires, unable to obtain a better physical condition.

Honoring Parents Lacks of Practical Action. Many college students' filial piety to their parents just stays in the oral, not really do in the specific actions, becoming filial piety action dwarf". For example, most college students back home clung to their parents, living like a parasite, and seldom help parents do housework, washing bowl, burning the food is never done, and even their parents make a bed for them. Parents often worry about their children's college life that is not used to take care of the body. But many students rarely take the initiative to care about their body, they immediately open the computer and listen music while coming back home, lacking communication and exchanges with parents.

Don't Cherish the Life from Their Parents. 《The Book of Filial Piety make clear at the outset chapter $\rangle$ the beginning of filial piety is being afraid to damage self-body which is all from parents. It means that human body limbs, hair, skin, are endowed by the parents, not to be damaged disability which is the beginning of filial piety. Life is not only a personal problem, but also a moral issue to honor their parents. Some students do not know how to cherish their precious lives and health, so naive as to think life is self-problem, none of other people's business and do what they like, Slowly the behavior sof undisciplined behavior, skipping classes and drinking, all night on the Internet come up, and even meeting setbacks prone to suicide Dutch act. Life is only once, so valuable, how could such a reckless tread on life? Cherishing life is also the starting point of filial piety, trampling on life is the greatest disrespect to parents.

\section{Analysis on the Reasons of the Lack of Filial Piety in College Students}

Facing with the current lack of college students "filial piety" the status quo, we had to have a deep thinking: what is the really reason that the current university students are missing "filial piety"? Why is it easy to know but difficult to do to honor their parents? To sum up, there are mainly the following four reasons:

The Influence of Social Atmosphere. With the deepening of globalization, international exchanges between China and the world are increasingly widespread, western liberalism, money worship, utilitarianism, hedonism, adverse ideological and moral concepts following them into the society of our country which has an important impact on China's College Students' filial piety. For example, money worship makes the students do not know how the "bread and water" austerity ", 
regardless of the parents' economic affordability, pursuit of high consumption, advance consumption. Some college students believe that supporting their parents is a burden, and even produce disgust, abandon the idea.

The Absence of School Education. no matter at kindergarten, primary school or at secondary schools, universities, Our educational content too much emphasis on teaching to the test, the pursuit of high scores, but ignore the learning gratitude, filial piety for parents' raising. Even if there is "filial piety" education, the idea of "filial piety" is twisted, instilling in students with a ideal that it is not filial respect for parents, do not respect if not good to learn, get the best academic performance. Filial piety education twisted by examination-oriented education force students to get scores at any cost, So they immerse in the sea of homework, but did not really understand the true meaning of filial piety.

Excess Love from Family. Due to the implementation of family planning for more than thirty years, a new generation of single child family evolved into a "4-2-1" structure (that is, four grandparents, two parents, one child). A child of the family become the center of gravity, is cared by six parents surrounded type, Who not only arrange home everything debris, and meet child's needs constantly. Days and months multiplying, children's consciousness of "self" as the center will swell up, become selfish and arrogant, will not take other people's feelings into account, naturally do not know how to honor and respect parents.

The Weakness of Students Themselves. Many college students believe that "filial piety", which will damage the independence of the personality. Because in the feudal society, the class that the father guide the child is to sacrifice their children's independence to improve the absolute authority of their parents. We chase freedom and equality and democracy in twenty-first Century, if like the feudal society to emphases filial piety, it will be too backward. At the same time, many college students are afraid to assume responsibility, lack responsibility. Traditional morality of filial piety, the requires college students to have a sense of responsibility to the parents, to have a sense of obligation to the society, and Love the nation and the country.

\section{Carry forward the Essence of Filial Piety, and Strengthen the Education of College Students' Filial Piety}

After analyzing the reasons of the lack of "filial piety", we need to actively carry forward the essence of filial piety, to strengthen the construction of campus culture.

Critically Carry forward the Essence of "Filial Piety". The so-called "filial piety is the first of all kindness", "Filial piety" is a leading position in Chinese traditional ethics, is one of the core of the Confucian classics culture, to seek that the beginning level is to honor parents, the second is to be loyal the king, the last is to cherish self, but all begin with honoring parents. Filial piety is a moral concept of feudal society; there is a positive side, a negative, a not scientific side. We should carry forward the essence and charm of "filial piety" critically

Then, our traditional "filial piety" essence of culture, the main focus on the following three aspects:

Firstly, filial piety requires children to honor parents.

Children to their parents filial piety, mainly includes three aspects: supporting for parents, respecting for parents, cheering parents. Specifically speaking, to support their parents is that when parents is old ,children need to do everything we can to take care of parents in economic life and spiritual care, making them live assurance, spiritual comfort, healthy body, enjoys the old age. Respecting for parents is a higher level of filial piety requirements, on the basis of "supporting", in accordance with the "etiquette" of the requirements and standards to honor their parents, obedience 
to their parents. Respecting and loving parents are the essence of the traditional filial piety, Supporting parents is simply and perform of external responsibility, but piously worshiping parents is a moral dimension and moral higher requirements of filial piety than supporting.

Secondly, Filial piety requires children to cherish valuable life given by their parents to

As mentioned in "The Analects of Confucius. For politics" Zheng Meng Wu asked about filial piety" Confucius answered: "parents very worry about children's diseases. It means that parents are very concerned about of their children; the whole world is full of worries about whether they are sick. As a child, we need to feel for others, in the care of their parents at the same time, also need to cherish their own body, life. First, college students should not be too fragile, when face any problems and setbacks, should bravely stand up, meet the challenge, should not a suicide, and hastily ended his own life. To live, to live well, is a kind of Thanksgiving.

Grasp the New Characteristics of Contemporary Filial Piety Culture. As the knowledge age of twenty-first Century, we need to re define the meaning of filial piety, and define the new characteristics of contemporary filial piety culture. Generally speaking, filial piety needs to return to its original meaning, return to the scope of family ethics, e combine with the times, to establish a new type of filial piety culture.

Firstly, filial piety needs to return to the original meaning of "respecting" and "raising" parents.

Modern society requires that filial piety cannot be excessive political and can't say filial relationship "minister is minister, father is father and son is son", but should return to the original meaning of the culture of filial piety, and return to the family content. Specifically speaking,

Filial piety chases "filially raising "and "filially respecting" parents

Secondly, filial piety needs to emphasize the equality between parents and children.

The traditional filial piety culture emphasizes that the father right is absolute authority, with the supreme leadership, that no one can give a negative and shake. If you dare to say to their parents a "no", it's to say that children is unfilially for parents. This will inevitably lead to the loss of equal rights of children; there is no freedom to speak of. This is "foolish filial piety", and is completely out of touch with modern society, relationship between parents and their children are free and equal, emphasis on children's parents "filial piety" at the same time, it also needs to emphasize the parents of children's "kindness", and the relationship between parents and their children is equal relationship.

Thirdly, filial piety needs to give parents spiritual care.

As the saying goes: "raise children for old time, collect rice for hungry time", Filial piety to parents first should be reflected in the "material support" this aspect. However, with the continuous development of social economy, in addition to the need to support their parents, but also need to give parents more care. As the age continues to increase, parents more rely on their children, want more time to eat together, talk about with heart. As children of college students, we must understand the emotional needs of parents; learn to respect them, to give their parents as much as possible care

Fourth, filial piety needs to emphasize the initiative and self-discipline "filial piety".

Filial piety and understanding of parents cannot rely solely on the external requirements of filial piety and restriction. Modern society requires the filial piety of parents, to come from the heart of their children, and actively implement the "filial piety" "are not with no the right and wrong, must obey the command of elders.

Strengthening the Concrete Implementation of Filial Piety Education of College Students.

Firstly, strengthen college students' rational understanding of filial piety. 
The implementation of filial piety needs the acquired education, to make the "filial piety" value be demonstrated under modern conditions, first of all, we should start with the cognition of "filial piety", to strengthen the rational understanding of the filial piety of College students, , absorb the essence of traditional culture of filial piety, and gradually establish the concept of "filial piety", And combine of modern life, and constantly updated, to enrich the knowledge of modern filial piety, To make college students realize the significance of modern filial piety for the value of life and the meaning of life, and to form a scientific concept of filial piety.

Secondly, strengthen college students' Cultivation of filial piety.

Filial piety is a kind of affection behavior, need from the heart, initiative ly to support their parents, respect for elders. So we in filial piety education for college students, not only need to pay attention to the cognitive education of "filial piety", but also need from flesh and blood affection of parents of filial piety of emotion nurturing, Let college students in the true family relationship to establish this filial affection, so that the unity of knowledge, emotion and meaning, and then use the actual action to achieve filial piety.

Thirdly, strengthen the practice of filial piety action of College students.

"Filial piety "is specious about practice. Filial piety is not only a kind of moral theory, but also a kind of behavior norm, which needs to be expressed in people's behavior. Therefore, we need to strengthen college students in their daily life to develop the habit of filial piety. Modern life is superior, contemporary college students rely more on their parents than their care and respect for. The ancient "filial piety" requirements for parents "visit one's parents day and night", "be very attentive to one's parents". In daily life to respect and care parents. In modern society, we need to also learn a lesson, in the daily life of filial piety, for example, to buy insurance for their parents, parents go out to travel, and urge parents to conduct regular physical examination and so on.

\section{References}

[1] Liu Huimin, Liu Yuli. The modern meaning of the concept of filial piety [J].The theory journal, 2005 (3)

[2] Pan Jian feng. discussion on filial morality and the construction of college students' Ideological and moral of [J]. Research on Higher Education in China, 2005 (9)

[3] He Guixin,Harmonious society and modern filial education in Colleges and universities [J].Educational exploration, 2007, (1)

[4] Deng Ling. Investigation and Study on the concept of filial piety of college students [J].Youth studies, 2000 (11)

[5] Lv Yanli, Zhang Lirong. Moral education and filial piety culture in Colleges and universities [J] Educational exploration, 2005 (1).

[6] Xie Ziyuan. On the innovation of filial piety and the construction of new filial piety.[D].Journal of Shihezi University.Philosophy and Social Science Edition.2007 (1).

Jia Fengzhen, teacher, lecturer in Xijing University general education center, mainly engaged in Ideological and political education of College students. 